\title{
Models of Hawaiian volcano growth and plume structure: Implications of results from the Hawaii Scientific Drilling Project
}

\author{
D. J. DePaolo \\ Department of Geology and Geophysics, University of California, Berkeley \\ E. M. Stolper \\ Division of Geological and Planetary Sciences, California Institute of Technology, Pasadena
}

\begin{abstract}
The shapes of typical Hawaiian volcanoes are simply parameterized, and a relationship is derived for the dependence of lava accumulation rates on volcano volume and volumetric growth rate. The dependence of lava accumulation rate on time is derived by estimating the eruption rate of a volcano as it traverses the Hawaiian plume, with the eruption rate determined from a specified radial dependence of magma generation in the plume and assuming that a volcano captures melt from a circular area centered on the volcano summit. The timescale of volcano growth is $t=2 R / v_{\text {plate }}$ where $R$ is the radius of the melting zone of the (circular) plume and $y_{\text {plate }}$ is the velocity of the Pacific plate. The growth progress of a volcano can be described by a dimensionless time $t^{\prime}=t v_{\text {plate }} / 2 R$, where $t^{\prime}=0$ is chosen to be the start of volcano growth and $t^{\prime}=1$ approximates the end of "shield" growth. Using a melt generation rate for the whole plume of $0.2 \mathrm{~km}^{3} / \mathrm{yr}$, a plume diameter of $50 \mathrm{~km}$, and a plate velocity of $10 \mathrm{~cm} / \mathrm{yr}$, we calculate that the lifetime of a typical volcano is $1000 \mathrm{kyr}$. For a volcano that traverses the axis of the plume, the "standard" dimensions are a volume of $57,000 \mathrm{~km}^{3}$, a summit thickness of $18 \mathrm{~km}$, a summit elevation of $3.6 \mathrm{~km}$, and a basal radius of $60 \mathrm{~km}$. The volcano first breaches the sea surface at $t^{\prime} \approx 0.22$ when it has attained only $5 \%$ of its eventual volume; $80 \%$ of the volume accumulates between $t^{\prime}=0.3$ and $t^{\prime}=0.7$. Typical lava accumulation rates start out over $50 \mathrm{~m} / \mathrm{kyr}$ in the earliest stages of growth from the seafloor, and level out at $\sim 35 \mathrm{~m} / \mathrm{kyr}$ from $t^{\prime} \approx 0.05$ until $t^{\prime}=0.4$. From $t^{\prime}=0.4$ to $t^{\prime}=0.9$, the submarine lava accumulation rates decrease almost linearly from $35 \mathrm{~m} / \mathrm{kyr}$ to $\sim 0$; subaerial accumulation rates are about $30 \%$ lower. The lava accumulation rate is a good indicator of volcano age. A volcano that passes over the plume at a distance $0.4 R$ off to the side of the plume axis is predicted to have a volume of about $60 \%$ of the standard volcano, a lifetime about $8 \%$ shorter, and lava accumulation rates about 15-20\% smaller. The depthage data for Mauna Kea lavas cored by the Hawaii Scientific Drilling Project are a good fit to the model parameters used, given that Mauna Kea appears to have crossed the plume about 15-20 km off-axis. The lifetime of Mauna Kea is estimated to be $920 \mathrm{kyr}$. Mauna Loa is predicted to be at a stage corresponding to $t^{\prime} \approx 0.8$, Kilauea is at $t^{\prime} \approx 0.6$, and Loihi is at $t^{\prime} \approx 0.16$. The model also allows the subsurface structure of the volcanoes (the interfaces between lavas from different volcanoes) to be modeled. Radial geochemical structure in the plume may be blurred in the lavas because the volcanoes capture magma from a sizeable cross-sectional area of the plume; this inference is qualitatively born out by available isotopic data. The model predicts that new Hawaiian volcanoes are typically initiated on the seafloor near the base of the next older volcano but generally off the older volcano's flank.
\end{abstract}

\section{Introduction}

This paper presents simple geometrical models for the growth of Hawaiian volcanoes. The objective is to quantify the relationships between volcano growth rates, mantle plume structure, velocity of the Pacific plate relative to the plume, and path of a volcano relative to the plume axis. The models described here allow the lava accumulation rate, which can be measured from drill core geochronology and other observations, to be used to evaluate the evolutionary stage of a vol-

Copyright 1996 by the American Geophysical Union.

Paper number 96JB00070.

0148-0227/96/96JB-00070\$09.00 cano. The geochemistry of the lavas can then be assigned to an evolutionary stage, and the changes in lava geochemistry during volcano growth can be related to the geochemical and thermal structure of the plume. Lava accumulation rate models can also be used to evaluate the intergrowth of contemporaneous volcanoes, and this information feeds back into the study of the volcano through drilling by aiding in drill site selection. Ultimately, the thermal and geochemical structure of the Hawaiian plume, the melting rates in the plume, the volcano growth histories and geochemical evolution, and the velocity of the Pacific plate relative to the plume must be selfconsistent if the plume model is to be considered an adequate description of the Hawaiian hot spot.

In order to fully evaluate the growth of volcanoes with time, 


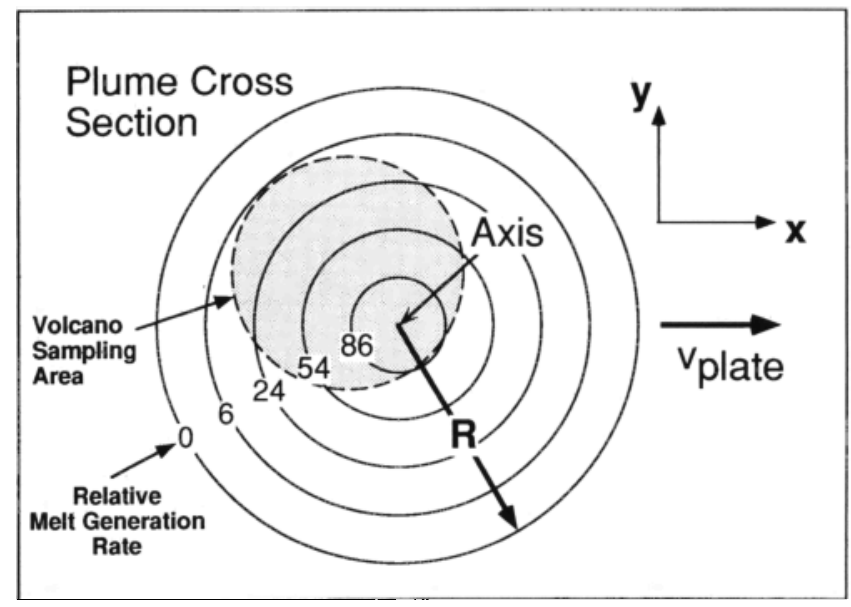

Figure 1a. Plan view of model circular plume with a melting zone of radius $R$, showing contours of melt generation rate; 100 is the rate at the plume axis. The $x$ and $y$ coordinate system used in the text is defined relative to the direction of plate motion over the plume. The coordinate $x$ represents the distance of the volcano summit from the plume axis along the $x$ direction. The shaded circle illustrates the area of the plume sampled by a single volcano at a single time.

it would be necessary to have long, well-dated stratigraphic sections through the lava sequences of several volcanoes that are overlapping in age. These data do not yet exist, but the systematic sampling and geochronology done as part of the Hawail Scientific Drilling Project (HSDP) phase 1 drilling in Hilo [DePaolo et al., 1991; Stolper et al., this issue] provides enough data on Mauna Kea so that there is now justification for developing more quantitative models. Despite decades of volcanological study, there is still disagreement about such basic questions as the lifetimes of individual volcanoes and the velocity of the Pacific plate. Estimates of volcano growth times vary from $\sim 600 \mathrm{kyr}$ to $1500 \mathrm{kyr}$ [Moore and Clague, 1992; Moore, 1987], and estimates of Pacific plate velocity of $13 \mathrm{~cm} / \mathrm{yr}$ over the past million years [Moore and Clague, 1992] contrast with the long-term estimates of $8-10 \mathrm{~cm} / \mathrm{yr}$ based on the age progression in the Hawaiian archipelago [MacDougall, 1964; Dalrymple et al., 1973; Clague and Dalrymple, 1987]. In any one region of the Hawaiian Ridge, it is arguable whether lavas from

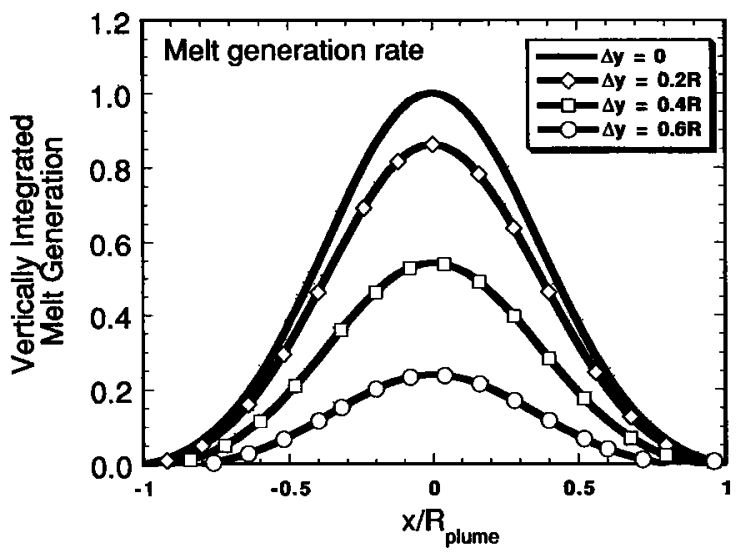

Figure 1b. Melt generation vs distance in the $x$ direction, showing curves for transects of the plume at different distances $(\Delta y)$ from the plume axis. two adjacent volcanoes are extensively interfingered or whether the growth of the older one was essentially complete before the younger one started forming. Even the obvious question about when the youngest volcanoes (Kilauea and Loihi) first started forming is open to debate. Simple, but quantitative, volcano growth models can contribute to resolution of all of these issues, although in general, appropriate data for evaluating some critical details of the models are not yet available.

The models discussed here can be considered quantifications of aspects of Hawaiian geodynamics and volcanology that are either fairly obvious or have been addressed to some degree in previous volcanological and geodynamic studies [Bargar and Jackson, 1974; Lipman, 1980, 1995; Moore, 1987; Walker, 1990; Lipman and Moore, this issue; Moore and Clague, 1992; Watson and McKenzie, 1991; Ribe, 1988]. The existence of a Hawaiian plume is accepted, and it is assumed to have radial symmetry. The issues addressed here follow from the plume model and geometrical constraints imposed by volcano shapes.

\section{Plume Structure and Magma Supply}

Models of mantle plume flow such as that of Watson and McKenzie [1991] or Hauri et al. [1994] attribute to the plume a radial structure consisting of a hot central core, with temperature decreasing radially outward from the plume axis. As the plume material is advected upward into the temperature range of melting, more magma is produced along the axis of the plume than at positions distant from the axis. The integrated amount of melt produced per unit cross section of the plume is described approximately by a Gaussian distribution as a function of radial distance $r$ from the plume axis [Watson and McKenzie, 1991]. As a volcanic center moves across the top of the plume the supply of magma to the volcano can be assumed to track the magma production rate in the plume, so that the eruption rate of the volcano starts out small, gradually increases to a peak value and then gradually decreases again to

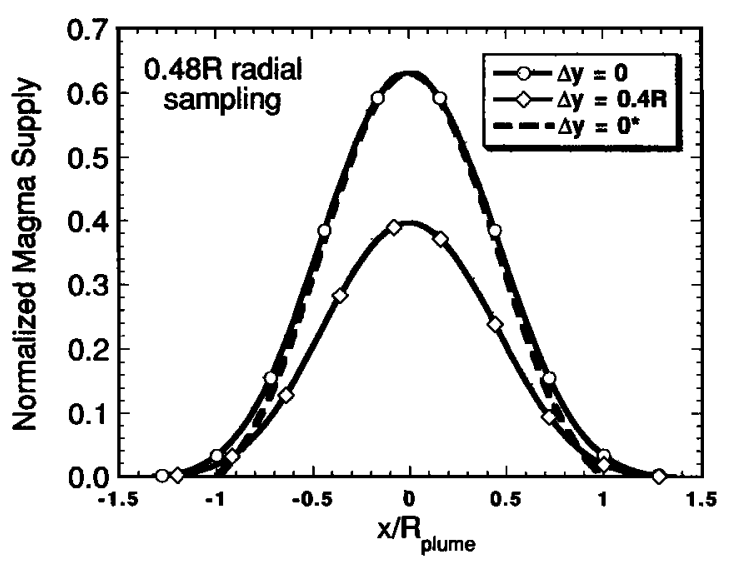

Figure 1c. Fraction of total plume melt production sampled by a volcano as it traverses the plume, for two values of $\Delta y$. This calculation is done with a sampling area of radius $0.48 R$ as shown in Figure 1a. The solid curves are the actual model values, which, for $\Delta y=0$, go to zero at $x / R= \pm 1.24$. The magma production values used for the calculations shown in Figures 5-10 were adjusted by subtracting the value at $x / R=$ \pm 1 and then renormalizing so that the peak magma supply is the same. The adjusted curve for $\Delta y=0$ is shown by the dashed line. 
zero [e.g., Frey et al., 1990; Lipman, 1995]. For the purposes of constructing a model, we assume that the magma production rate per unit area of the plume is described by the following function of $r$ :

$$
G(r)=G(0) \exp \left(-r^{2} / a^{2} R^{2}\right) \cos (\pi r / 2 R),
$$

which is close to a Gaussian distribution but truncated at $r=$ $R$, the nominal plume radius. The value of $G(0)$ is chosen so that the total plume melt production is appropriate, and we use $a=0.64$ which is arbitrary. For Hawaii the total melt production $G_{\text {plume }}$ is believed to be about 0.1 to $0.2 \mathrm{~km}^{3} / \mathrm{yr}$ [Moore, 1987; Watson and McKenzie, 1991]. The region of high sublithospheric temperature associated with the plume is drawn into a teardrop shape in plan view by the movement of the lithosphere over the plume [Ribe and Christensen, 1994], but it is uncertain whether the melting region is similarly deformed. We retain the radial symmetry for the modeling and comment below on the effects of a teardrop geometry.

The amount of magma supplied to an individual volcano per unit time is some fraction of $G_{\text {plume}}$, depending on the horizontal distance over which melt can be focused to a single volcano and the path of the volcano summit over the plume. Figure 1a shows schematically the assumed plume cross section. Figure 1b shows the normalized magma generation rate, $G(r) / G(0)$, as a function of $x$, where $x$ represents the position of the volcano summit ( $x=0$ in the plane normal to the plate velocity vector and including the plume axis), and for different values of $\Delta y$, where the latter is the offset in the $y$ direction relative to the plume axis. Figure 1c shows the normalized magma supply for a single volcano $G_{v} / G_{\text {plume }}$, for a volcano passing over the plume axis $(\Delta y=0)$ and assuming the volcano captures magma from an area described by a circle of radius $0.48 R$ centered on the volcano summit (see Figure 1a). If the volcano path over the plume is offset by $0.4 R$ from the plume axis, the model predicts that the total volume of the volcano is about $60 \%$ that of a volcano that passes directly over the plume axis. For $G_{\text {plume }}=0.2 \mathrm{~km}^{3} / \mathrm{yr}$, this model gives a maximum eruption rate of about $0.13 \mathrm{~km}^{3} / \mathrm{yr}$ for $\Delta y=0$ and $0.08 \mathrm{~km}^{3} / \mathrm{yr}$ for $0.4 R$. For a given value of $G_{\text {plume }}$ the size of a volcano is determined by $\Delta y$ and the plate velocity in this model.

\section{Geochemical Sampling of the Plume}

Entrainment of surrounding mantle material may give the plume a radial chemical and isotopic structure that has some similarities to the radial temperature structure [Hauri et al., 1994, this issue]. A volcano traversing the plume samples the radial chemical structure systematically, but the geochemical signal is smeared because of the size of the sampling area. Figure 2 shows how a volcano having a $0.48 R$ radius sampling area expresses radial plume structure (an isotopic ratio) depending on its path over the plume. Figure 2 is calculated assuming that the plume chemical structure mimics the temperature structure and assuming that the concentrations of elements of interest do not vary with position in the plume. The important point is that, at any time, a volcano samples a substantial fraction of the plume and therefore may never erupt lavas that are perfectly representative of the central plume. Furthermore, if the sampling area model is relevant, there should be systematic differences, for example, between Mauna Loa and Mauna Kea when compared at an equivalent

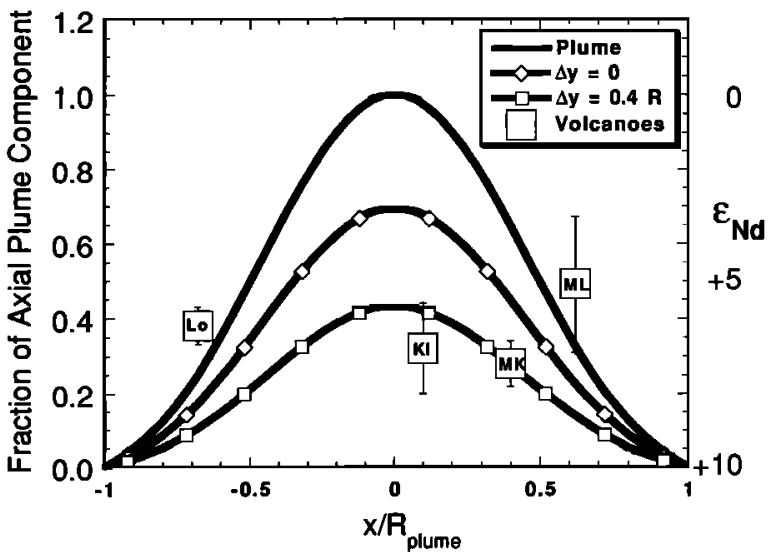

Figure 2. Effect of smearing of radial geochemical structure in the plume as sampled by a volcano for two different values of $\Delta y$. The actual assumed plume structure is shown by the top curve; the middle and bottom curves represent the sampling as seen by the volcanoes. The right scale shows $\varepsilon_{\mathrm{Nd}}$ values, which might vary from 0 to +8 from the plume center to the rim. For the volcano sampling area used, the lowest value that might be found in the lavas would be about +2.5 for a volcano traversing the plume axis and +5 for a volcano that traverses the plume off to the side of the axis. The squares show average $\varepsilon_{\mathrm{Nd}}$ values for Mauna Loa (ML), Mauna Kea lavas from deep in the HSDP core (MK), historic Kilauea lavas (Ki), and dredged Loihi lavas (Lo). The squares have been placed on the horizontal axis based on lava accumulation rates (see Figures 8 and 9).

stage of growth [Lassiter et al., this issue; Hauri et al., this issue]. As discussed elsewhere in this section [DePaolo, this issue; Hauri et al., this issue] chromatographic effects in the melting zone in the plume may further complicate the geochemical signal in the lavas. As shown in Figure 2 and discussed elsewhere, there is evidence of systematic differences between Mauna Loa and Loihi, which are close to the Hawaiian Ridge axis, and Mauna Kea and Kilauea, which are displaced from the ridge axis.

\section{Volcano Growth and Lava Accumulation Rates}

One of the primary observations from the drill core record is the lava accumulation rate [Sharp et al., this issue]. In order to assess the implications of the accumulation rate it is instructive to compare it with the predictions of a simple geometric model of volcano growth, using the typical shape of a volcano [e.g., Peterson and Moore, 1987; Mark and Moore, 1987] and the magma supply rates described above. In general, Hawaiian volcanoes are elongate rather than circular in plan view. Nevertheless, we describe the shape of a volcano using an axisymmetric form shown in cross section in Figure 3. If the volcano is elliptical rather than circular in plan view, the radii as used here would be equivalent to the square root of the product of the major and minor radii of the ellipse. The volcano cross section is described by the outward slopes of the subaerial part of the volcano (slope $=\alpha$ ) and the submarine flank of the volcano (slope $=\beta$ ) and the inward slope of the base of the volcano (slope $=\gamma$ ). An additional parameter is also used, the depth $h_{\mathrm{m}}$ of the moat measured at the base of the volcano flank, which accounts for the fact that the entire surface of the lithosphere is depressed by the weight of the volcano out to a distance that is greater than the volcano radius [Walcott, 1970; 


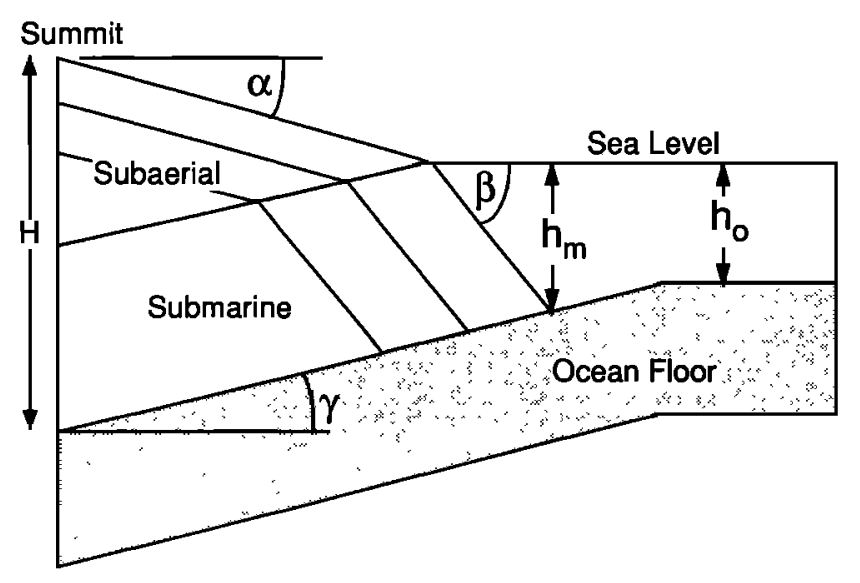

Figure 3. Model parameters to describe the shape and size of a radially symmetric volcano. The volcano profile is based on the model of Peterson and Moore [1987].

Watts, 1978]. The depth $h_{\mathrm{m}}$ is determined from the original ocean depth $h_{0}$ and the summit thickness of the volcano $H$ by

$$
h_{\mathrm{m}}=h_{0}+m H,
$$

and we have used a value, $m=0.03$, which gives a qualitative fit to the depth of the moat. From studies of volcano slopes [Mark and Moore, 1987], the values for $\alpha$ and $\beta$ are in the range $4^{\circ}-9^{\circ}$ and $10^{\circ}-18^{\circ}$, respectively, and based on seismic studies, the value of $\gamma$ is about $6^{\circ}-10^{\circ}$ [Moore, 1987; Lipman and Moore, this issue]. According to the models of Peterson and Moore [1987], the volcanoes grow as steep-sided cones before they breach the ocean surface. After breaching the surface the slopes of subaerial flows are smaller, but the relatively steep submarine slopes are maintained as the volcano builds its ediface outward.

An implication of the geometry shown in Figure 3 is that isostatic adjustment of the lithosphere is fast in comparison to the growth rate of the volcanoes. As new lava is stacked onto the top of the lithosphere, it is assumed that there is immediate compensation by subsidence. The assumption of rapid isostatic adjustment is acceptable if, as argued below, the volcano growth times are of order $10^{6}$ years, since the timescale for isostatic adjustment of the oceanic lithosphere is less than $10^{4}$ years [Turcotte and Schubert, 1982]. The specific shape shown in Figure 3 in effect specifies the amount of subsidence per unit loading. We have not tried to determine the specific relationship between loading and subsidence implied by the geometrical model, and of course, the flexural properties of the lithosphere are only crudely represented by the model in any case. It is not obvious whether a more detailed representation of the lithospheric response to loading would be worthwhile for the purposes discussed here, since the other geometrical complications caused by overlapping volcanoes probably outweigh any advantages that could be gained by improved subsidence models.

For the axisymmetric shape (Figure 3 ) the volume of the volcano $(V)$ is related to the summit thickness of the volcano $(H)$ by

$$
V_{1}=\frac{\pi H^{3}}{3}\left[\frac{\cot ^{3} \beta \cot ^{2} \gamma+\cot ^{3} \gamma \cot ^{2} \beta}{(\cot \beta+\cot \gamma)^{3}}\right]
$$

when $H$ is less than the thickness $\left(H_{\text {breach }}\right)$ needed to breach the sea surface and

$$
H_{\text {breach }}=h_{0}\left[\frac{\cot \gamma}{\cot \beta+\cot \gamma}-m\right]^{-1} .
$$

After the volcano has grown above the sea surface, the volume is related to the summit thickness by

$$
V_{2}=\frac{\pi}{3}\left[h_{1}^{3}\left(1+\frac{\cot \gamma}{\cot \beta}\right) \cot ^{2} \gamma+h_{3}^{3}\left(1-\frac{\cot \alpha}{\cot \beta}\right) \cot ^{2} \alpha\right]
$$

where

$$
\begin{gathered}
h_{1}=\frac{\left[H(1-m)-h_{0}\right] \cot \alpha+\left(h_{0}+m H\right) \cot \beta}{\cot \gamma+\cot \alpha} \\
h_{3}=H(1-m)-h_{0}-h_{1} .
\end{gathered}
$$

Using these relationships, it is possible to calculate model lava accumulation rates as a function of the volumetric growth rate of the volcano, assuming that the volcano grows by adding lava uniformly to its entire surface at all times. Because of the difference in slope, the subaerial and submarine accumulation rates are different. The subaerial accumulation rate $H_{\mathrm{a}}$ is related to the submarine accumulation rate $H_{\mathrm{m}}$ by

$$
H_{\mathrm{m}}=H_{\mathrm{a}} \frac{\tan \gamma^{\prime}+\tan \beta}{\tan \gamma^{\prime}+\tan \alpha},
$$

where $\gamma^{\prime}$ is the slope of the subaerial-submarine transition (Figure 2), which we take as equal to $\gamma$.

Because the volcanoes overlap, and sometimes grow concurrently, the base of almost every volcano is not the original ocean floor, but a combination of the ocean floor and the flank of an older volcano. Growth on or against another volcano affects the relationship between volcano summit thickness $H$ and volume expressed by (5). Because the number of possible configurations is limitless, it is difficult to generalize, but we can estimate the effects for simple geometrical models and then apply an approximate correction factor to (5). One simplified limiting case is shown in Figure 4, where a conical volcano $B$ has grown on the flank of a previous volcano $A$, and at the end of growth of volcano $B$ the two volcanoes have the same height and radius. The older volcano (A) displaces a fraction, $\Delta V / V_{\mathrm{B}}$ of the volume of volcano $\mathrm{B}$, where $V_{\mathrm{B}}$ is the volume that would be predicted based on a right-circular conical shape. The fractional volume displacement $\Delta V / V_{\mathrm{B}}$ is dependent on the parameter $f=d / R$, where $2 d$ is the spacing of the volcano summits and $R$ is the basal radius of the cones. If the older cone is complete at the time of inception of growth of the younger cone, then the expression for the volume displacement for the fully grown younger volcano is

$$
\frac{\Delta V}{V_{\mathrm{B}}}=\frac{6}{\pi} \int_{0}^{1 /}(f+x)^{2} \cos 1\left(\frac{f}{f+\frac{x}{3}}\right)-f x^{1 / 2}(x+2 f)^{1 / 2} d x
$$

If the two volcanoes grow simultaneously, the volume displacement is half that given by (9) (Figure 4b). For Hawaiian volcanoes the typical summit spacing is $40-50 \mathrm{~km}$ and the basal radius is a little larger, so the parameter $f$ takes on values of 0.4-0.5 and the fractional volume displacement is between about $10 \%$ and $35 \%$. For the case where the older volcano is fully or mostly grown when the younger volcano commences growth, the fractional volume displacement could be somewhat larger than shown in Figure $4 \mathrm{~b}$ for the early stages of growth of 
volcano $\mathrm{B}$, since the older volcano has a larger radius but will approach that given by (4) as the volcano grows. Many Hawaiian volcanoes grow against two or even three other volcanoes. A rough rule is that the actual volcano volume is smaller by about $30 \%$ than what would be calculated from its summit thickness by (5).

Figure 5 shows the relationships between summit thickness, summit elevation, volcano volume, and volcano radius, using two sets of slope angles and multiplying the volume calculated from (5) by 0.7 . The differences between the two sets of curves illustrate the effect of choosing different values for the volcano slopes. The approximate dimensions applying to seven of the youngest Hawaiian volcanoes are indicated by the placement of the corresponding initials across the top of the figure. Note that the model volcanoes grow to a substantial height above the seafloor $(5 \mathrm{~km})$ and a large corresponding summit thickness $(8-9 \mathrm{~km})$ while the volume is still quite small $(<3000$ $\left.\mathrm{km}^{3}\right)$.

\section{Saddle Evolution and Interfingering of Lavas}

Simultaneous growth of adjacent volcanoes leads to the possibility of interfingering of lavas. Quantification of the degree
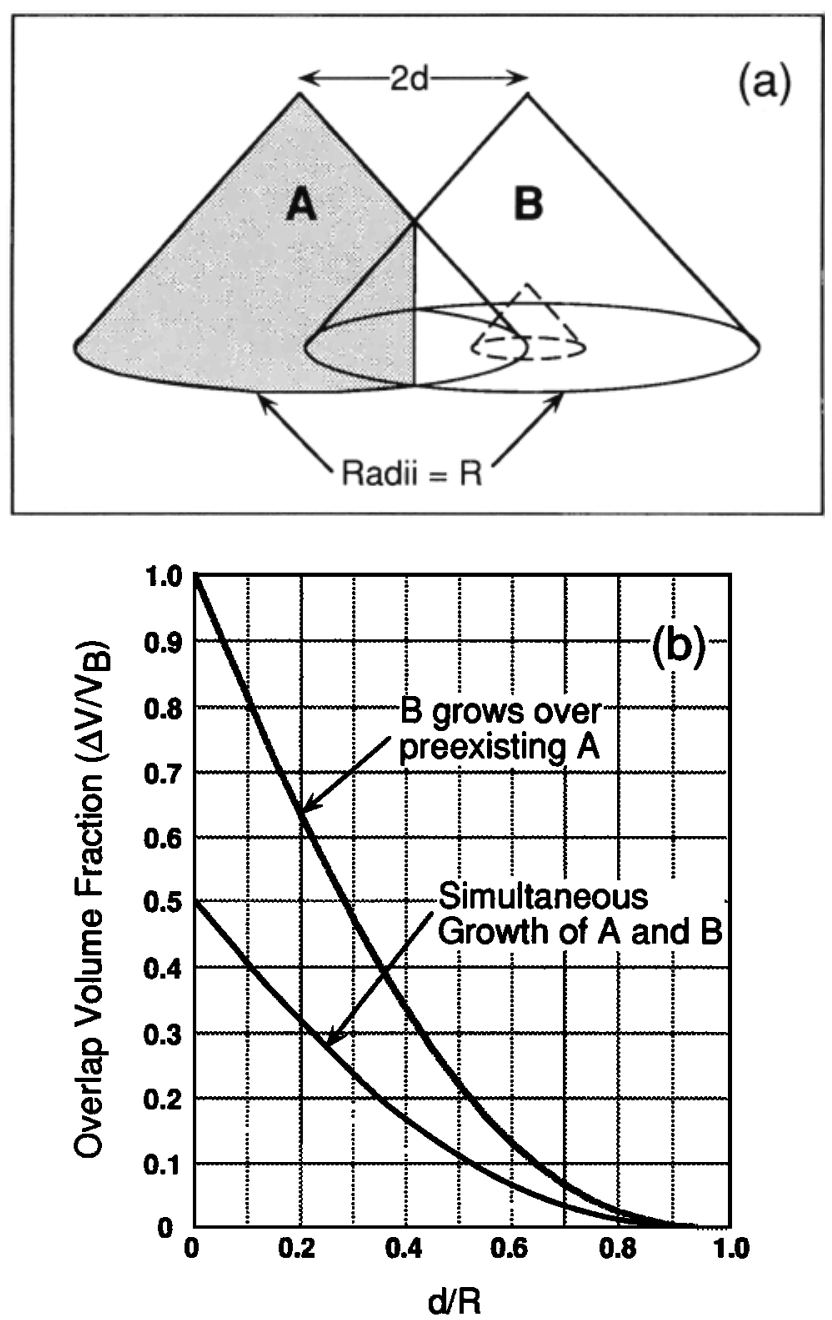

Figure 4. (a) Model of overlapping right circular cones for estimating overlap volume of two adjacent volcanoes of similar height and radius. (b) Missing volume fraction of volcano B; curves are based on equation (9).
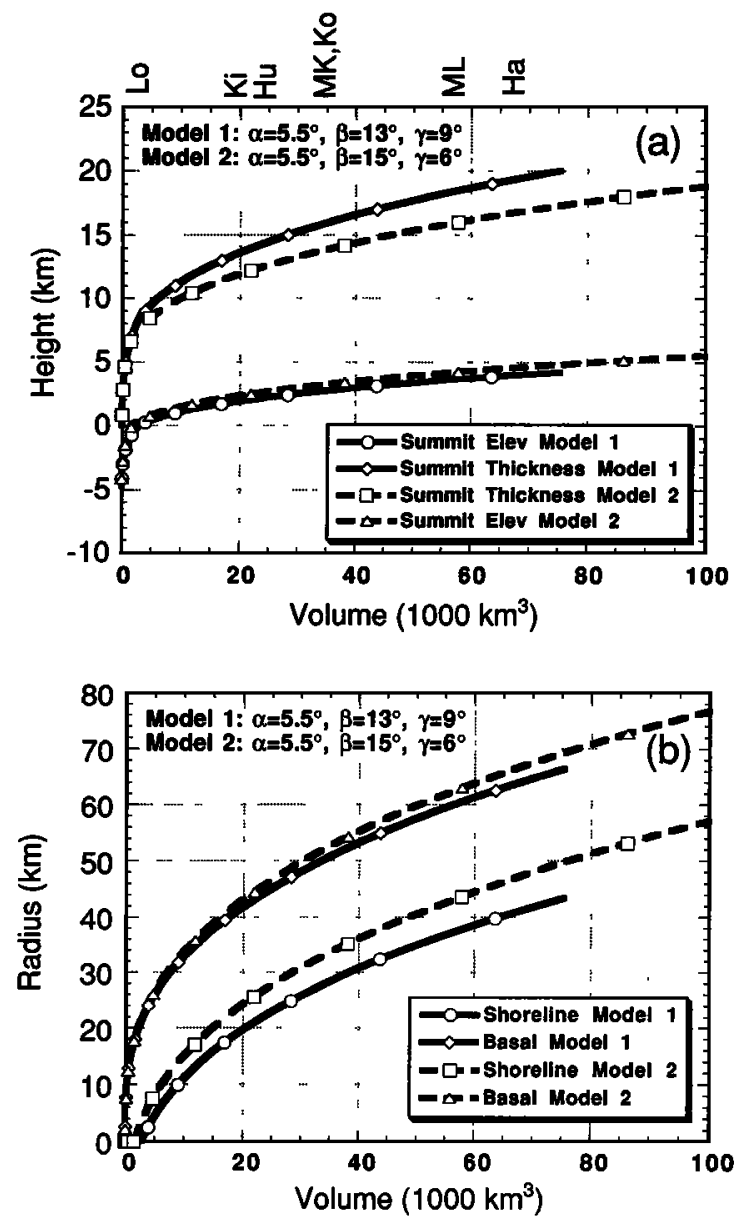

Figure 5. (a) Relationship between summit thickness ( $H$ in Figure 3), summit elevation above sea level, and volcano volume assuming a missing overlap volume fraction of 0.3 (see Figure 4). Model 1 incorporates the "standard" slopes, and model 2 represents a volcano whose thickness is smaller relative to its radius. In both models the volcano volume is about $2500 \mathrm{~km}^{3}$ at the time the summit reaches sea level. The abbreviations for the volcanoes are Lo, Loihi; Ki, Kilauea; Hu, Hualalai; MK, Mauna Kea; Ko, Kohala; ML, Mauna Loa; Ha, Haleakala. (b) Basal radius and shoreline radius of model volcanoes versus volcano volume, where the volume here (as in Figure $5 \mathrm{a}$ ) is reduced by $30 \%$ to account for overlap with older volcanoes.

of interfingering is useful for assessing the subsurface shape (and therefore the volumes) of the volcanoes and for assigning provenance to lava core derived from drilling. The geometric problem of predicting the subsurface shape of the interface between two volcanoes is somewhat complicated but is relatively simple if one starts by considering the shape of the interface in the plane connecting the summits of two adjacent volcanoes. The interface between two volcanoes represents the trace of the topographic "saddle" through space as the volcanoes grow. The parameters governing the saddle evolution are the slopes of the volcano surfaces and the relative lava accumulation rates of the two volcanoes. Relative to a fixed horizon in the volcanoes, the vertical velocity of the saddle between two volcano summits is a function of the slope-weighted sum of the lava accumulation rates, and the horizontal velocity of the saddle location is related to the difference in lava accumulation 


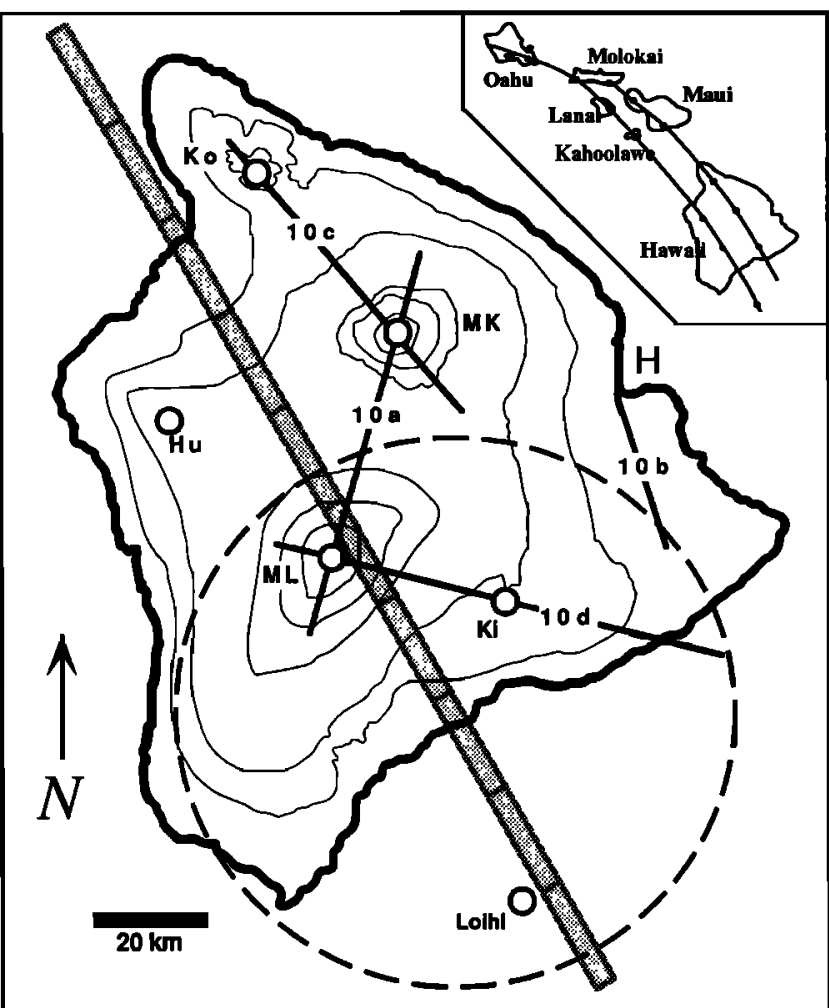

Figure 6. Map of the island of Hawaii showing topography and locations of volcano summits (circles). The shaded, segmented bar oriented $\mathrm{N} 30^{\circ} \mathrm{W}$ represents the model trace of the plume axis, which corresponds to the seismically defined axis of the Hawaiian Ridge [Moore, 1987]. The segments represent $20-\mathrm{km}$ intervals. The dashed circle shows the boundary of a plume melting region of $50-\mathrm{km}$ radius, with the center located so that the active volcanoes Loihi, Kilauea (Ki), and Mauna Loa (ML) are positioned appropriately for their model ages and eruption rates as discussed in the text. The positions of the cross-section lines of Figure 10 are shown by the labeled heavy lines. Other symbols are Ko, Kohala summit; Hu, Hualalai summit; MK, Mauna Kea summit; H, Hilo Bay. Inset shows the traces of the "Loa" and "Kea" trends.

rate between the volcanoes. For two volcanoes (a and $b$ ) with lava accumulation rates $H_{\mathrm{a}}$ and $H_{\mathrm{b}}$, and surface slopes $\alpha_{\mathrm{a}}$ and $\alpha_{\mathrm{b}}$, the saddle velocities are

$$
\begin{gathered}
v_{\mathrm{s}, z}=\frac{H_{\mathrm{a}} \tan \alpha_{\mathrm{b}}+H_{\mathrm{b}} \tan \alpha_{\mathrm{a}}}{\tan \alpha_{\mathrm{b}}+\tan \alpha_{\mathrm{d}}} \\
v_{\mathrm{s}, x}=\frac{H_{\mathrm{a}}-H_{\mathrm{b}}}{\tan \alpha_{\mathrm{s}}+\tan \alpha_{\mathrm{b}}}
\end{gathered}
$$

for the vertical $(z)$ and horizontal $(x)$ directions, respectively. At any time, the slope of the interface in the vertical plane containing the two summits is therefore

$$
\alpha_{\mathrm{ab}}=\arctan \left(\frac{H_{\mathrm{a}} \tan \alpha_{\mathrm{b}}+H_{\mathrm{b}} \tan \alpha_{\mathrm{a}}}{H_{\mathrm{a}}-H_{\mathrm{h}}}\right) .
$$

The width $(\Delta x)$ of the zone of interfingering between the lavas of the two volcanoes can be estimated from the typical time interval between lavas $\left(\Delta t_{r}\right)$ and the slopes by

$$
\Delta x=\frac{H_{\mathrm{a}} \Delta t}{\tan \alpha_{\mathrm{a}}+\tan \alpha_{\mathrm{b}}},
$$

where $H_{\mathrm{a}}$ and $\alpha_{\mathrm{a}}$ refer to the more slowly growing volcano. During shield building, when the recurrence interval is less than 1000 years and the accumulation rates are $\sim 30 \mathrm{~m} / \mathrm{kyr}$ (see estimates below), the width of the interfingering zone is predicted to be only about $200 \mathrm{~m}$ in the plane connecting the volcano summits if the slopes are of order $5^{\circ}$. In fact, it can be more than this because the cone slope may lessen near the saddle.

To determine the interface slope in an arbitrary plane using (5) or (6), it is necessary to use the slopes of the volcano surfaces projected into that plane. In general, the lavas of adjacent volcanoes will be interfingered only over a restricted horizontal distance; therefore the subsurface interface should be defineable to within 300 to $1000 \mathrm{~m}$ or so, its width increasing with distance from the plane containing the volcano summits. An uncertainty of $\pm 1 \mathrm{~km}$ or even $\pm 2 \mathrm{~km}$ in the horizontal location of an interface is not significant for defining the subsurface shapes of volcanoes with radii of order $50 \mathrm{~km}$.

\section{Generic Volcano Growth Models}

In order to obtain first estimates of lava accumulation rates, we take the plume radius $R$ as $50 \mathrm{~km}$ and the Pacific plate velocity as $10 \mathrm{~cm} / \mathrm{yr}$. The plate velocity used is somewhat larger than the $8.6 \mathrm{~cm} / \mathrm{yr}$ estimated from the age-distance relations for the Hawaiian part of the Hawaii-Emperor chain but less than the value of $13 \mathrm{~cm} / \mathrm{yr}$ recently proposed by Moore and Clague [1992]. The diameter of the plume is uncertain but can be estimated from the current volcanic activity and from dynamical models. Watson and McKenzie [1991] estimated that the zone of net melting under the plume had a radius of close to $50 \mathrm{~km}$. At the present time there is active volcanism at Loihi and Hualalai volcanoes, which are $100 \mathrm{~km}$ apart (Figure 6). Based on the models discussed here, Loihi is expected to have traversed about $15-20 \%$ of the way across the plume. The Loihi-Hualalai separation would suggest a minimum plume diameter of $115 \mathrm{~km}$. However, Mauna Kea, which is about 95 $\mathrm{km}$ from Loihi, has had a negligible eruption rate for about 100 kyr [Frey et al., 1990]. Thus the existing patterns of volcanism are reasonably consistent with a plume radius of $50 \mathrm{~km}$. Although the models discussed below use $R=50 \mathrm{~km}$ and $v_{\text {plate }}=10 \mathrm{~cm} / \mathrm{yr}$, the results apply to any combination that gives the same value of $R / v_{\text {plate }}=500 \mathrm{kyr}$.

To calculate the time evolution of a volcano, it is assumed that the eruption rate is given by curves such as those in Figure 1c, but with the curves modified slightly so that the eruption rate goes to zero at $x= \pm R$. Figure 7a shows how the volume of a model volcano increases with time as it passes over the plume; the example shown is for a "standard" volcano passing over the plume axis with $2 R / v_{\text {plate }}=1000 \mathrm{kyr}$, and for a fractional volume displacement of $30 \%$ due to the presence of older volcanoes. The values of $\alpha, \beta$, and $\gamma$ used for this calculation were $5.5^{\circ}, 13^{\circ}$, and $9^{\circ}$. Figure 7 a also shows summit thickness and height above sea level as a function of normalized time $t^{\prime}\left(=t v_{\text {plate }} / 2 R\right)$. For $G_{\text {plume }}=0.2 \mathrm{~km}^{3} / \mathrm{yr}$, the standard volcano when fully grown has a total volume of 57,000 $\mathrm{km}^{3}$, a summit thickness of $18 \mathrm{~km}$, a basal radius of $60 \mathrm{~km}$, and a height above sea level of $3.6 \mathrm{~km}$; values that correspond reasonably well to those of Mauna Loa [Lipman, 1995]. The predicted summit elevation is a poor fit to the observations, because in reality the volcanoes become relatively tall near the end of their evolution when lava accumulation becomes restricted to the near-summit area rather than covering the en- 


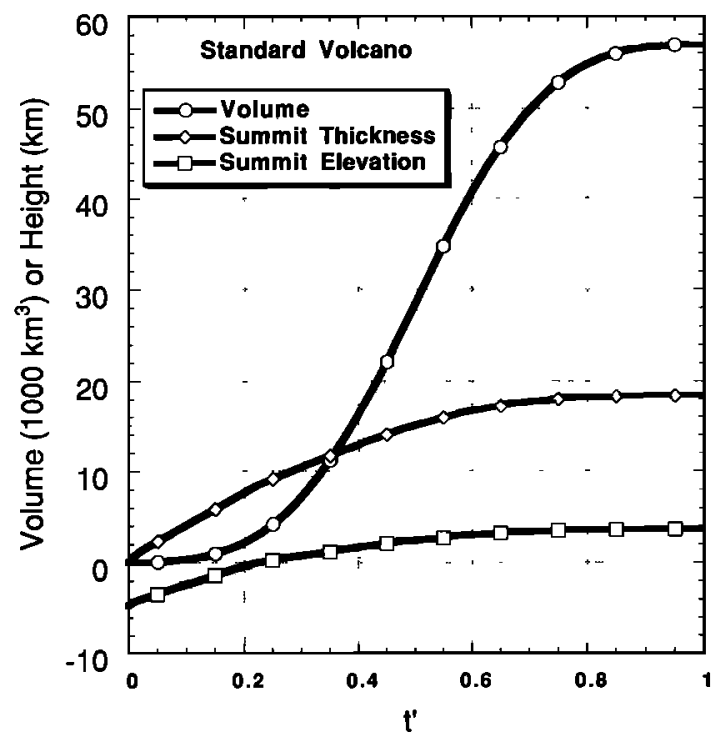

Figure 7a. Evolution with time of the volume, summit thickness, and summit elevation of a "standard" volcano as it passes over the plume $(\Delta y=0)$. The slope parameters used are those of model 1 given in Figure 5. The volume shown is reduced by $30 \%$ relative to that which would be calculated from equation (5) and the summit thickness. The dimensionless timescale is set such that $t^{\prime}=1$ corresponds to the time it takes for the volcano summit to traverse the plume. Note that the model volcano breaches the sea surface at $t^{\prime}=0.22$.

tire shield [Lipman, 1995]. The appropriate elevation for comparison of the model would be that obtained by projecting the lower slopes of the volcano to the summit position.

Figure $7 \mathrm{~b}$ shows the lava accumulation rate against normalized time for the standard volcano. The accumulation rate starts out above $50 \mathrm{~m} / \mathrm{kyr}$ (or $50 \mathrm{~mm} / \mathrm{yr}$ ) when the volcano is initiated on the ocean floor and then decreases rapidly to about $35 \mathrm{~m} / \mathrm{kyr}$ where it stays for about half the growth time of the volcano. Since the lava accumulation rate is approximately proportional to $G_{v} V^{-2 / 3}$, it becomes gradually smaller in the late stages of volcano growth even if the eruption rate is still

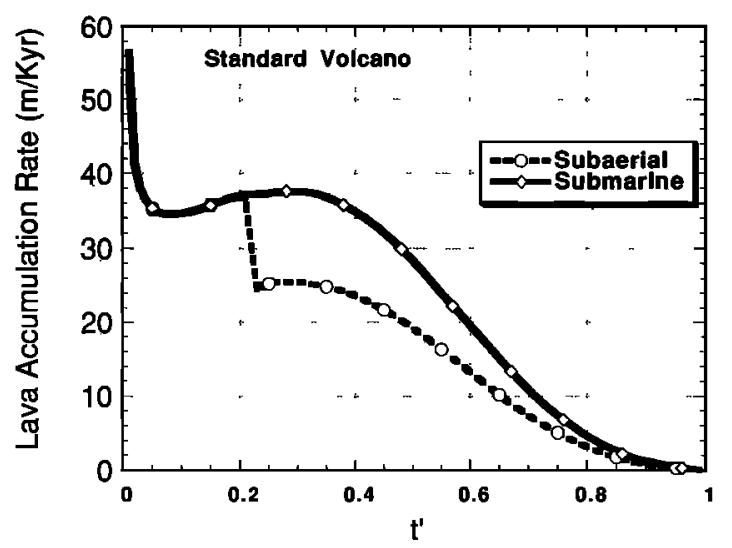

Figure 7b. Calculated values of lava accumulation rate versus $t^{\prime}$. The rates shown correspond to a plume traverse time $\left(2 R / v_{\text {plate }}\right)$ of $1000 \mathrm{kyr}$. After the volcano breaches the sea surface there are two accumulation rates, one applicable to the subaerial part of the volcano and another applicable to the steeper submarine slopes.

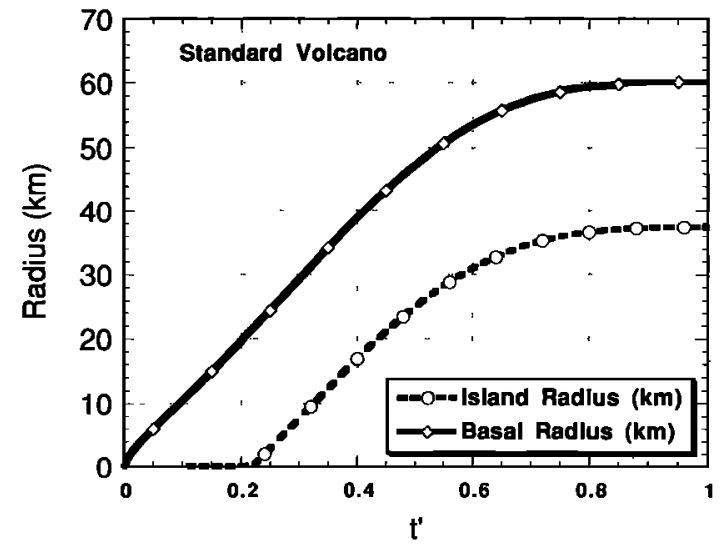

Figure 7c. Radii of the "standard" volcano versus $t$ ".

high. The combined effects of decreasing eruption rate and increasing surface area cause the lava accumulation rate to decrease almost linearly from $t^{\prime}=0.4$ to $t^{\prime}=0.9$. The last third of a volcano's lifetime is characterized by lava accumulation rates that are 3-10 times slower than those of the first third of its lifetime. The subaerial accumulation rates are calculated to be about $30 \%$ lower than the corresponding submarine accumulation rates.

Figure 7c shows how the radii of the volcano, to the base on the seafloor, and to the shoreline, increase with time. Mauna Loa, for example, has major and minor radii of roughly 50 and $30 \mathrm{~km}$, as measured from the summit toward the southwest and southeast respectively, which are close to the model prediction of a $38-\mathrm{km}$ radius. The predicted basal radius of a standard volcano at $t^{\prime}=0.4$ to 0.6 is 40 to $54 \mathrm{~km}$. The spacing of volcano summits is also about $40-60 \mathrm{~km}$. The model therefore predicts that new volcanoes begin to form very close to the base of the next older volcanoes. The radial growth rate from $t^{\prime}=0$ to $t^{\prime}=0.5$ is almost exactly equal to the plate velocity of $10 \mathrm{~cm} / \mathrm{yr}$, whereas at $t^{\prime}>0.5$ the radial growth rate becomes less than the plate velocity. If the spacing of the volcanoes is determined by the time delay before inception of the next volcano, then when the time delay is greater than $0.5 t^{\prime}$, the new volcano will tend to form directly on the Cretaceous ocean floor rather than on the flank of the older volcano. Loihi appears to have formed very close to the base of Mauna Loa, which accords with the model. Kohala, whose inception appears to have been delayed relative to that of Haleakala, was established well away from the base of Haleakala.

The fact that new volcanoes appear close to the base of the next older volcano means that in general, the older volcanoes extend laterally under the younger ones to a point within about $5-10 \mathrm{~km}$ of the summit location of the younger volcano. Because the lava accumulation rate for a new volcano starts out very high (Figure $7 \mathrm{~b}$ ), the new volcano quickly establishes its cone above the surface of the older volcano. The distance between the summit of the new volcano and the saddle between it and the older volcano initially increases rapidly to about $5-8 \mathrm{~km}$, at which point the lava accumulation rate of the younger volcano is not much different from that of the older volcano (Figures $7 \mathrm{~b}$ and $7 \mathrm{c}$ ); thereafter it will be maintained at that value or increase slowly. As the two volcanoes grow concurrently, the interface between the two volcanoes (in the vertical plane including the two summits) is steep for several kilometers upward from the base of the volcanoes because the 

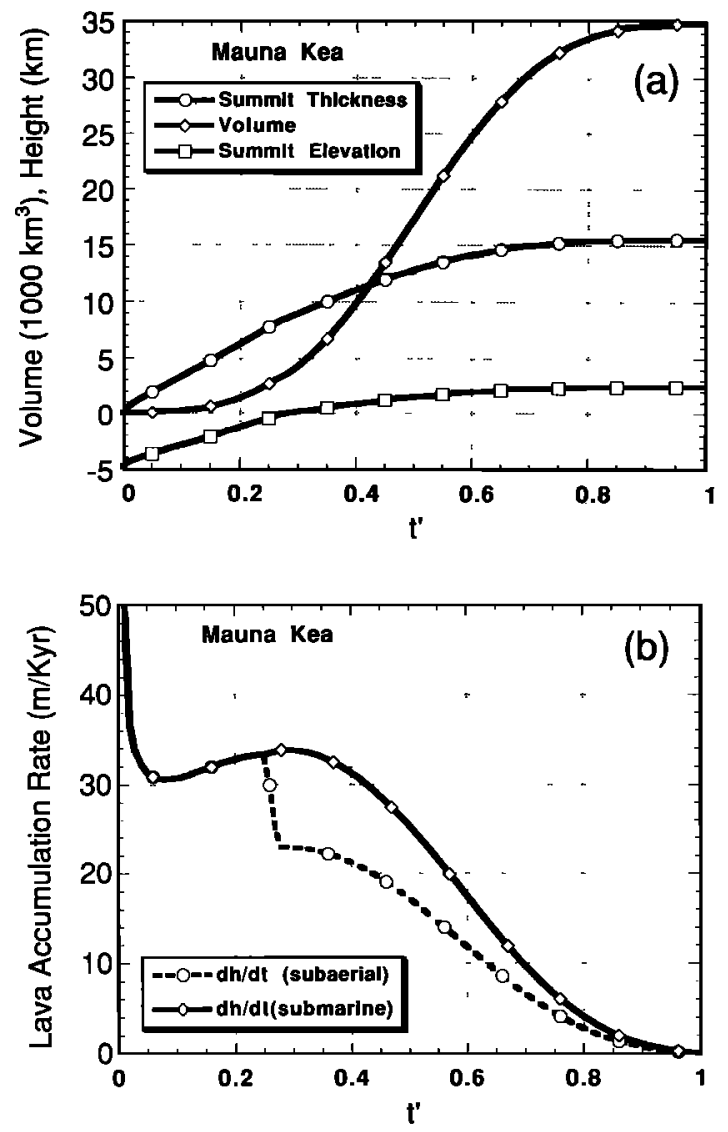

Figure 8. (a) Model evolution of volume, summit thickness and summit elevation with parameters appropriate for Mauna Kea volcano. The predicted summit elevation of about $2.5 \mathrm{~km}$ is lower than the actual elevation of $>4 \mathrm{~km}$, but the model prediction is close to what the Mauna Kea summit elevation would be if the late alkalic cap of the volcano (which has particularly steep slopes) were removed. (b) Model Mauna Kea lava accumulation rates, assuming that the plume traverse time $\left(2 R^{\prime} / v_{\text {plate }}\right)$ is $920 \mathrm{kyr}$. The lifetime and volume of Mauna Kea are predicted to be smaller than those of the standard volcano because Mauna Kea did not pass directly over the plume axis (see Figure 6).

lava accumulation rates will be similar for the two volcanoes. As the lava accumulation rate of the older volcano declines, the younger one will gradually prograde up the slope of the older volcano. The last $40 \%$ or so of the growth time of the younger volcano will be done against an essentially extinct older volcano, and in this interval the interface between the volcanoes is the surface of the older volcano at the time it ceased to grow.

The conclusions outlined above do not take account of landslides, the elongate shape of most volcanoes, or the possibility that the plume output ( $\left.G_{\text {plume }}\right)$ varies with time. These can be taken into account where there are geologic data and should be if models such as this are to be used to address more specific issues.

\section{Lifetime of Mauna Kea}

If the trace of the axis of the Hawaiian plume is located using the axis of the Hawaiian Ridge as imaged by seismic refraction data [Moore, 1987], then the Mauna Kea summit lies about $15-20 \mathrm{~km}$ off to the side of the plume axis (Figure 6). For a plume radius of $50 \mathrm{~km}$ and $\Delta y=20 \mathrm{~km}$, the peak eruption rate for Mauna Kea should be about 0.4 to $0.45 G_{\text {plume }}$, or 0.08 to $0.09 \mathrm{~km}^{3} / \mathrm{yr}$ for $G_{\text {plume }}=0.2 \mathrm{~km}^{3} / \mathrm{yr}$. The width of the plume at a point $20 \mathrm{~km}$ off axis is about $92 \%$ of the diameter, so the model lifetime of Mauna Kea is $2 R^{\prime} / v_{\text {plate }}$, where $R^{\prime}=$ $0.92 R$. For $R / v_{\text {plate }}=500 \mathrm{kyr}$, the model lifetime of Mauna Kea is $920 \mathrm{kyr}$ and its model volume is $35,000 \mathrm{~km}^{3}$. The model volume is close to that estimated by Frey et al. [1990]. The model values for size and lava accumulation rate for Mauna Kea are shown in Figure 8.

Figure 9 shows the calculated model age-depth relationship for the Mauna Kea subaerial lavas compared with the Ar-Ar and K-Ar ages of Sharp et al. [this issue]. There is some difficulty in comparing the two profiles because the model age of the end of Mauna Kea volcanism is somewhat arbitrary. The geochronological data are quite consistent with the accumulation rate that is predicted by the model, and the inferred evolutionary stage reached at the bottom of the HSDP drill core corresponds to $t^{\prime} \approx 0.7$ (Figure $8 \mathrm{~b}$ ). However, it might be expected that the actual lava accumulation rate is higher than the model value, because in the late stages of shield growth, lava may be distributed over a surface area that is smaller than the full area of the volcano [cf. Lipman and Moore, this issue]. If, for example, the Mauna Kea lavas corresponding to the section in the drill core were restricted to an area extending to about $5-10 \mathrm{~km}$ radially outward of the shoreline, the lava accumulation rate would be about 1.5-2 times the model value for the same eruption rate (but the accumulation rate on the lower submarine slopes would be zero). On the other hand, the late life of a volcano may also be characterized by a high proportion of intrusive as opposed to extrusive growth, which would tend to offset the other effect. Restriction of the late Mauna Kea shield lavas to the subaerial and near-shore area would help explain the geochemical differences between dredged Mauna Kea lavas and those encountered in the drill core [Lassiter et al., this issue; Yang et al., 1994, this issue; Rhodes, this issue]. Extrapolation of the Mauna Kea age-depth relations to greater depth is shown in Figure $9 \mathrm{~b}$. For this projection, the subaerial-submarine transition is placed at 1150 $\mathrm{m}$ depth, which is based on the location of the submarine slope break east of Hilo and the model slope of $9^{\circ} \mathrm{W}$ of the subaerialsubmarine transition. The model prediction is that the age of the lava resting on the Cretaceous seafloor at a depth of 5.5-6 $\mathrm{km}$ is about $700 \mathrm{ka}$. The model estimate of the age of inception of Mauna Kea volcano is about 1050 ka (Figure 8b).

The age-depth relation for the HSDP drill core lavas is consistent with the model parameters used here: $R / v_{\text {plate }} \approx$ $500 \mathrm{kyr}$. The data are not as consistent with the proposal of Moore and Clague [1992] that the plate velocity is $13 \mathrm{~cm} / \mathrm{yr}$, and the volcano lifetimes are $\sim 600 \mathrm{kyr}\left(R / v_{\text {plate }} \approx 325 \mathrm{kyr}\right)$, although there is still uncertainty about the ages at the bottom of the drill core, and the real test would come from age determinations deeper in the section (Figure 9b). However, there are problems with the Moore and Clague [1992] timescale in any case, which can be appreciated in the context of the models presented here and the HSDP data. Moore and Clague suggest that "somewhat before $400 \mathrm{ka}$," the Mauna Kea summit barely breached the sea surface, whereas the drill core data show that the shoreline at $\sim 400-420 \mathrm{ka}$ was located east of Hilo, more than $40 \mathrm{~km}$ from the summit. The Moore and Clague [1992] model requires a lava accumulation rate for Mauna Kea of about $40 \mathrm{~m} / \mathrm{kyr}$ between 400 and $300 \mathrm{ka}$, whereas the HSDP 
data suggest that it was about $7 \mathrm{~m} / \mathrm{kyr}$. The Moore and Clague [1992] model would require that the eruption rate of Mauna Kea for the $400-300 \mathrm{ka}$ interval be about $0.4 \mathrm{~km}^{3} / \mathrm{yr}$, about 4 times the estimated value for Kilauea.

\section{Subsurface Structure of the Island of Hawaii Shape of Mauna Kea}

The lava accumulation model and the information from the HSDP drill core allow calculation of the position of the Mauna Loa-Mauna Kea interface (Figures 9a and 9b). Using the standard volcano model (Figure 6) to describe Mauna Loa, and the model of Figure 8 for Mauna Kea, the position of the ML-MK saddle can be backtracked through time using equations (10). The age difference between Mauna Loa and Mauna Kea is taken to be about $300 \mathrm{kyr}$, based on the $320 \mathrm{ka}$ age of the Mauna Kea lavas from the drill core at a depth of $400 \mathrm{~m}$, and the observation that the lava accumulation rate at the $400-\mathrm{m}$ level is approximately analogous to that for the modern Mauna Loa [Lipman, 1995]. The $300 \mathrm{kyr}$ age difference is also consistent with a $10 \mathrm{~cm} / \mathrm{yr}$ plate velocity and the fact that Mauna Kea is about $30 \mathrm{~km}$ farther to the northwest (along the trend of the Hawaiian Ridge axis) than is Mauna Loa (Figure 6). Figure 10 a shows a profile in the plane containing the volcano summits. The model predicts that Mauna Kea extends from the crest of the present saddle to a point about $5-10 \mathrm{~km}$ northwest of the summit caldera of Mauna Loa. If Mauna Kea actually had a larger volume than currently estimated, or had a shorter lifetime relative to Mauna Loa, the resulting higher accumulation rates would move the interface a few kilometers closer to the Mauna Kea summit at its deepest point. Simultaneously changing the timescale of accumulation of both volcanoes does not significantly affect the resulting location of the interface, it just changes the ages of the lavas as a function of depth. For the model parameters used, the age of the lavas at the base of the interface is about 750-800 ka. Most likely, Mauna Loa started forming directly on the Cretaceous ocean floor at 800 ka, since neither Mauna Kea nor Hualalai would have been large enough to extend to the position of the current Mauna Loa summit unless perhaps Hualalai had a rift zone extending in the right direction.

Modeling of the Mauna Loa-Mauna Kea interface in the region near the drill hole is of interest because of the question of whether Mauna Loa lavas might be reentered at depth after entering them at the extrapolated level of the Mauna Kea surface ( $280 \mathrm{~m}$ in the drill core). Figure $10 \mathrm{~b}$ shows a calculated profile in the plane extending $\mathrm{S} 15^{\circ} \mathrm{E}$ from the present mouth of the Wailuku River in Hilo (see Figure 6). Calculation of the interface location indicates that Mauna Kea extends $25 \mathrm{~km}$ or more to the southeast under Mauna Loa. Owing to the fact that the slope of the Mauna Loa lavas is small $\left(\sim 1^{\circ}\right.$ in the plane of the section, which is almost tangential to the Mauna Loa cone), Mauna Kea lavas would occasionally flow out relatively far to the Mauna Loa side of the calculated interface, but the steeper slope of the Mauna Kea surface would prevent Mauna Loa lavas from extending significantly far toward the Mauna Kea summit side of the calculated interface. The model predicts that in the Hilo area, there is no chance of reencountering Mauna Loa lavas once Mauna Kea lavas have been entered.

The calculated Kohala-Mauna Kea interface is shown in Figure 10c. Since Kohala is $\mathbf{4 0} \mathrm{km}$ northwest of Mauna Kea, it might be expected that it is about 400 kyr older (see Figure 6).
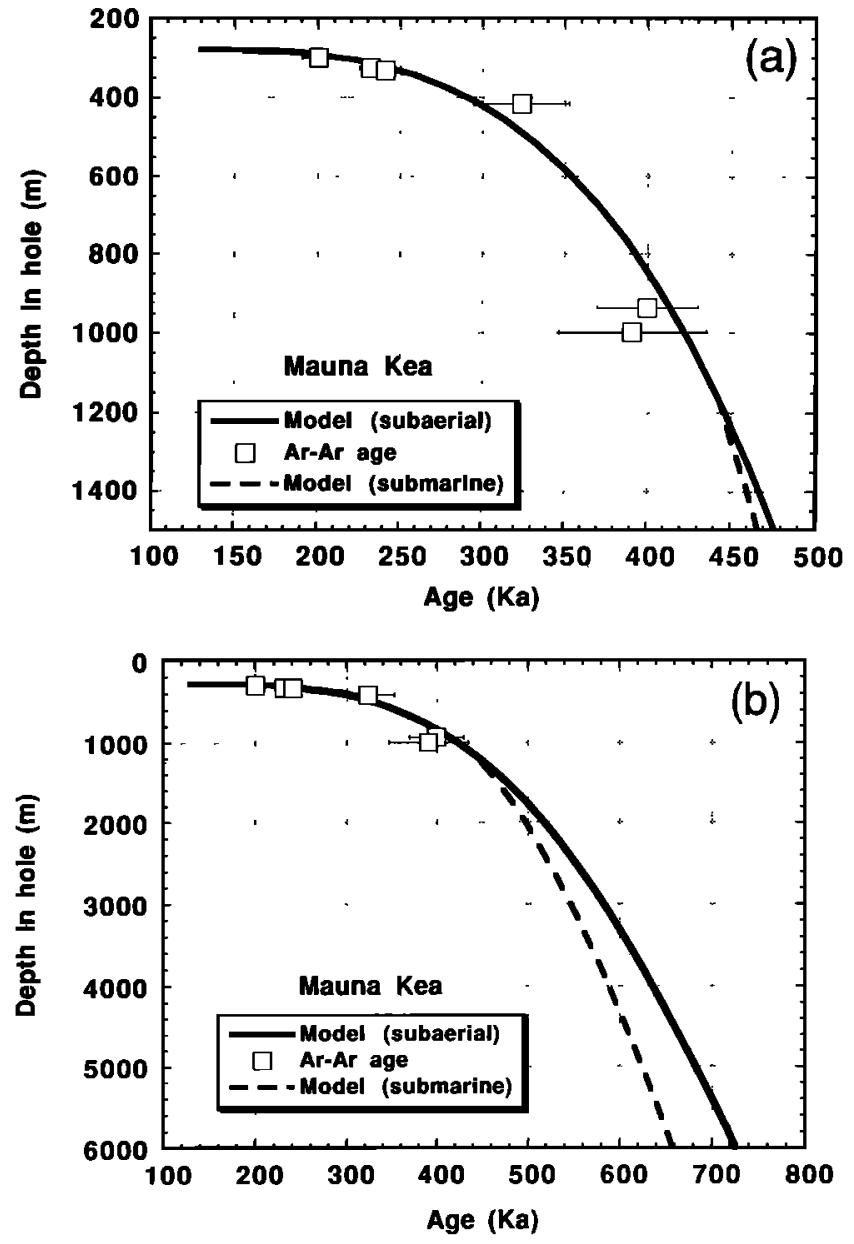

Figure 9. (a) Model depth-age curve for Mauna Kea and measured Ar-Ar ages of lavas [from Sharp et al., this issue]. The endpoint of the Mauna Kea curve is set somewhat arbitrarily to an age of $130 \mathrm{ka}$; but in any case the model curve is reasonably compatible with the data. (b) Model depth-age curve for Mauna Kea calculated to the depth of the underlying Cretaceous ocean floor (about $6 \mathrm{~km}$ ). The transition to submarine lava is expected to be at $1100-1200 \mathrm{~m}$ depth, so the dashed curve should apply at depths below that.

However, existing evidence suggests that Kohala is not that much older than Mauna Kea [Moore and Clague, 1992; Clague and Dalrymple, 1987]. The large amount of overlap between Kohala and Mauna Kea and the lack of overlap between Kohala and Haleakala might mean that Kohala's inception was delayed so that it is somewhat younger than it should be. Using an age difference of $250 \mathrm{kyr}$, Kohala projects less than $20 \mathrm{~km}$ toward the Mauna Kea summit. For the larger age difference, Kohala projects to a point almost directly below the Mauna Kea summit. These models suggest that it is highly unlikely that Kohala lavas extend as far as the Hilo drill site, which is 40 $\mathrm{km}$ from the Mauna Kea summit on the side opposite Kohala. Even if Kohala had a very long rift zone extending toward Hilo, there would not have been time to accumulate a significant thickness of lava there before Mauna Kea started growing.

\section{Kilauea and Loihi}

The growth models presented here can be extended to Kilauea and Loihi, to gain some insight as to their past and 

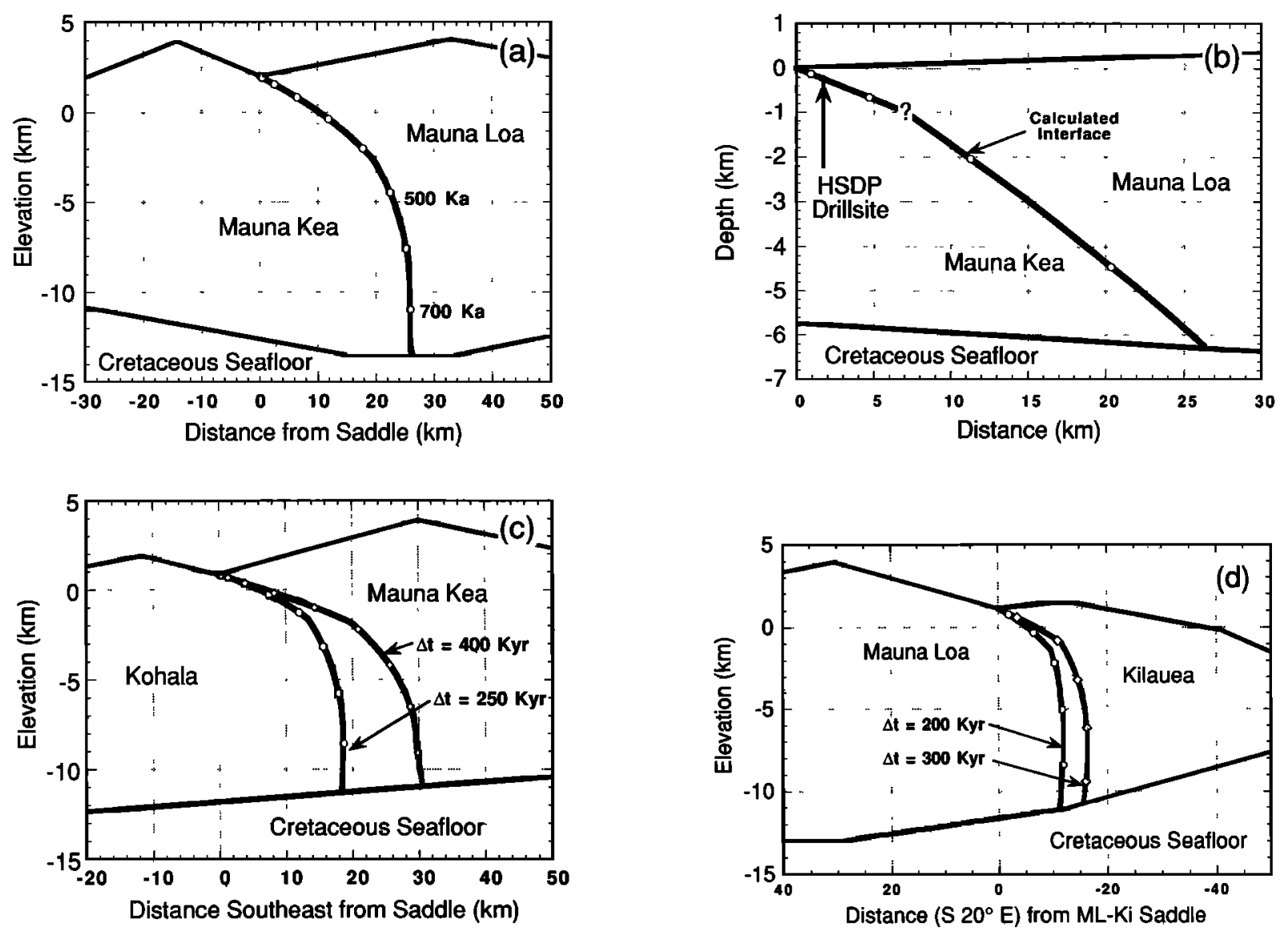

Figure 10. (a) Calculated location of the interface between Mauna Kea and Mauna Loa lavas in the vertical plane containing the summits (see equations (10) and (11)), assuming that Mauna Loa is 300 kyr younger than Mauna Kea as indicated by the HSDP results. Surface elevation profiles are schematic. (b) Calculated interface between Mauna Kea and Mauna Loa in the area near the HSDP drill site. The left-hand edge of the diagram is located where the present contact between the two volcanoes meets the shoreline in Hilo, and the profile extends to the southeast from there. The change in slope of the profile is controlled by the paleoshoreline of Mauna Kea, the depth of which is uncertain but probably close to $1 \mathrm{~km}$ in the plane of the section. (c) Calculated intersummit interface between Kohala and Mauna Kea assuming that Kohala is either 250 kyr or $400 \mathrm{kyr}$ younger than Mauna Kea. (d) Calculated intersummit interface between Mauna Loa and Kilauea assuming that the age difference between the volcanoes is either $200 \mathrm{kyr}$ or $300 \mathrm{kyr}$. Locations of all cross sections are shown in Figure 6.

future growth histories. Current opinion seems to favor the idea that Kilauea is relatively young, perhaps $200 \mathrm{kyr}$ or less old [Moore and Clague, 1992; Lipman, 1995]. However, given its position relative to Mauna Loa, Kilauea should be only about 200 to $250 \mathrm{kyr}$ younger than Mauna Loa (Figure 6). If the age of Mauna Loa is $820 \mathrm{kyr}$, the age of Kilauea should be about 600 kyr. Figure 10d shows calculated interfaces for Kilauea and Mauna Loa along the plane connecting the summits, assuming age differences of 200 and $300 \mathrm{kyr}$. For the 200-kyr age difference, the interface steepens under the Kilauea summit and extends down to the old ocean floor some $12 \mathrm{~km}$ below. For a 300-kyr age difference, the interface is slightly farther east. Even for the 200-kyr age difference, the summit of Kilauea appears to be too close to the saddle, since it should be at least about $5-10 \mathrm{~km}$ east (to the right on the figure) of the location of the base of the interface. This indicates that there is some problem with the model or that the Kilauea summit has recently moved westward toward Mauna Loa. The latter may be likely since even if Kilauea is younger than $200 \mathrm{ka}$, its high eruption rate should have caused the saddle to migrate farther from the summit than it currently is. Using equation (10b) and assuming that Kilauea has the typical young volcano lava accumulation rate of $35 \mathrm{~m} / \mathrm{kyr}$, the saddle should have migrated up the Mauna Loa slope a distance of 20 $\mathrm{km}$ per $100 \mathrm{kyr}$. The current distance is only about $5 \mathrm{~km}$. A more appropriate position for the Kilauea summit would be at the bend in the east rift zone near the Pu'u O'o vent, which would be about $18 \mathrm{~km}$ from the saddle.

The models suggest that there is nothing inherently problematical with the age of Kilauea being $600 \mathrm{kyr}$; in which case it has probably been in growth competition with Mauna Loa for a long time, only recently beginning to prograde up the Mauna Loa slope as the Mauna Loa eruption rate declines. Given that the eruption rates for Kilauea should be similar to or slightly larger than those for Mauna Kea, the model suggests that Kilauea is about $60 \%$ of the way through its active shieldbuilding lifetime $\left(t^{\prime}=0.6\right)$, that its current eruption rate is about $0.09 \mathrm{~km}^{3} / \mathrm{yr}$, its volume about 20,000 to $25,000 \mathrm{~km}^{3}$ (Figure 8), and its subaerial lava accumulation rate about 12 to $15 \mathrm{~m} / \mathrm{kyr}$ and decreasing. The historical eruption rate is esti- 
mated at about $0.1 \mathrm{~km}^{3} / \mathrm{yr}$ [Clague and Dalrymple, 1987] and the volume is estimated to be somewhat less than $20,000 \mathrm{~km}^{3}$ [Lipman, 1995]; estimates of the lava accumulation rates and total volume are uncertain but not far from the model values.

There is at present no direct evidence for the age of Loihi [Moore and Clague, 1992; Lipman, 1995]. The standard volcano model can be used to estimate Loihi's dimensionless age based on its summit elevation of $-1 \mathrm{~km}$. The model values fit reasonably well for $t^{\prime}=0.16$ (an age of $160 \mathrm{kyr}$ for $R / v_{\text {plate }}=500$ kyr; see Figure 6), which corresponds to a volume of about $1000 \mathrm{~km}^{3}$, a basal radius of $16-18 \mathrm{~km}$, a summit thickness of 6 $\mathrm{km}$, and a lava accumulation rate of about $35 \mathrm{~m} / \mathrm{kyr}$ (Figure 7). The model basal radius and summit thickness for Loihi are consistent with the bathymmetric and seismic data; the lava accumulation rate is about 3 times higher than that predicted for Kilauea. The model prediction is that Loihi will breach the sea surface in about $50 \mathrm{kyr}$.

\section{Summary and Conclusions}

We have attempted to predict the nature of Hawaiian volcano growth by constructing a straightforward geodynamic model where a moving (carried by the Pacific plate) volcano is fed by a radially symmetric mantle plume. The constraints on (or calibration of) the model come from the age-depth relationship determined for Mauna Kea lavas from the Hawaii Scientific Drilling Project 1-km core hole, comparison of the HSDP data with lava accumulation rates of Mauna Loa, and by taking account of the total volumes and typical shapes of Mauna Kea and other Hawaiian volcanoes, the estimates of long-term Pacific plate velocities, the structure of the Hawaiian Ridge as evidenced by seismic refraction data, and models for the melt production in the Hawaiian plume.

The fundamental timescale of the geodynamic volcanogrowth problem is given by $R / v_{\text {plate }}$, where $R$ is the radius of the magma production zone in the plume and $v_{\text {plate }}$ is the overriding lithospheric plate velocity. The time needed for a volcano being carried by the Pacific plate to traverse the plume top if it passes directly over the plume axis is just $2 R / v_{\text {plate }}$. The observed age-depth relations in the Mauna Kea lava sequence drilled by HSDP are fit well by the model for $2 R / v_{\text {plate }}=1000 \mathrm{kyr}$ and a total plume melt production of 0.2 $\mathrm{km}^{3} / \mathrm{yr}$. The growth progress of an individual volcano can be measured in terms of the dimensionless parameter $t^{\prime}=t v_{\text {plate }}$ $2 R$, where we take $t^{\prime}=0$ to be when the volcano first starts to form and $t^{\prime}=1$ is the end of shield building.

A "standard" volcano passing over the plume axis should attain a volume of about $57,000 \mathrm{~km}^{3}$, and correcting for the growth interference from neighboring volcanoes, its final prealkalic summit height is about $3.6 \mathrm{~km}$ and its basal radius about $60 \mathrm{~km}$. The volcano first breaches the sea surface at $t^{\prime} \approx 0.22$, when it has attained only about $5 \%$ of its eventual volume. About $80 \%$ of the volumetric growth occurs between $t^{\prime}=0.3$ and $t^{\prime}=0.7$. Typical submarine lava accumulation rates vary systematically with $t^{\prime}$; after an initial early phase with accumulation rates over $50 \mathrm{~m} / \mathrm{kyr}$, the rates level off at $35 \mathrm{~m} / \mathrm{kyr}$ from $t^{\prime}=0.05$ to $t^{\prime}=0.4$, and then drop almost linearly to zero at $t^{\prime}=0.9$ to 1.0. Subaerial lava accumulation rates are about $30 \%$ lower because of the geometry of the volcanoes (the subaerial slopes are much less steep than the submarine slopes). A volcano passing over the plume $0.4 R$ off to the side of the plume axis will be about $60 \%$ of the volume of the "standard" volcano, have a lifetime that is about $10 \%$ shorter, and have lava accumulation rates that are about $15-20 \%$ lower. On the basis of lava accumulation rates, Mauna Loa appears to be at a growth stage corresponding to $t^{\prime}=0.80$ to 0.85 , so it is $\mathbf{9 8 - 9 9 \%}$ of full volume and presumably has an age of about $800-850 \mathrm{ka}$. Considering the $10 \mathrm{~cm} / \mathrm{yr}$ plate velocity, Kilauea should be at a growth stage corresponding to $t^{\prime} \approx 0.6$, which would mean its age is about $550-600 \mathrm{ka}$ and it is currently at about $70 \%$ of full volume. Loihi is expected to be at the stage corresponding to $t^{\prime}=0.16$ (age of $160 \mathrm{ka}$ and about $3 \%$ of full volume).

The model results imply that volcanoes typically start growth on the seafloor close to the base of a preexisting volcano but normally not on the preexisting volcano's submarine slope. The bases of the older volcanoes are predicted to extend under the younger overlapping volcanoes to a point within about $10 \mathrm{~km}$ of the summit location of the younger volcano. When the model is applied to the youngest volcanoes, we calculate that the boundary between Mauna Loa and Kilauea is nearly vertical and just a few kilometers to the Mauna Loa side of the Kilauea summit.

Because each volcano samples a substantial cross-sectional area of the plume at any one time, if the plume has a radial geochemical structure, this structure is expected to be represented in the lavas in a subdued form due to the mixing of components derived from different radial positions in the plume. Depending on the detailed radial structure of the plume, the axial plume component may or may not appear undiluted in the lavas, and in any case will not be seen in volcanoes like Mauna Kea whose summits pass over the plume many kilometers to the side of the plume axis. Although the physics governing the shape and size of the magma collection area of a volcano are poorly known, an ad hoc model of a circular collection region of $\sim 50-\mathrm{km}$ diameter, produces geochemical patterns resembling those observed.

In order to build a more advanced model relating plume structure to volcano growth and composition, one needs to be able to predict the initiation of volcanoes and their subsequent magma supply and to have a better model for the geometry of the plume melting zone. The summits of Hawaiian volcanoes are not equally spaced, so there is likely to be a stochastic component to the problem of when volcanoes are initiated. The plume, which we have modeled as circular, is more likely to have a teardrop shape with the tail pointing northwestward as a result of the upper mantle flow [cf. Ribe and Christensen, 1994], and relative to the circular plume model, the volcanoes may get initiated relatively late and have a drawn-out senescence [Lipman, 1995]. If the latter is true, as we suspect, then the end-of-growth datum for volcanoes is likely to be an unreliable age indicator for estimating plate velocity unless the age difference between volcanoes is large compared to a volcano lifetime. The volcano growth that would result from an asymmetric melting region would tend to modify the model results described here mainly in the early stages of growth, so that the volcanoes would breach the sea surface faster.

Acknowledgments. This research was supported by NSF grants EAR-9118932 and EAR-9117588; it benefitted from many interactions with scientists associated with the Hawaii Scientific Drilling Project, and especially from FAX, phone, and e-mail discussions with Jim Moore in the course of preparing numerous proposals since 1986. One of us (D. J. D.) benefitted greatly from a Fulbright Fellowship to Australia National University during completion of this work. The manuscript benefitted from a careful review by Dave Clague. 


\section{References}

Bargar, K. E., and E. D. Jackson, Calculated volumes of individual shield volcanoes along the Hawaiian-Emperor chain, J. Res. U.S. Geol. Surv., 2, 545-550, 1974.

Clague, D. A., and G. B. Dalrymple, The Hawaiian-Emperor volcanic chain, I, Geologic evolution, U.S. Geol. Surv. Prof. Pap., 1350, 5-54, 1987.

Dalrymple, G. B., E. A. Silver, and E. D. Jackson, Origin of the Hawaiian Islands, Am. Sci., 61, 294-308, 1973.

DePaolo, D. J., High-frequency isotopic variations in the Mauna Kea tholeiitic basalt sequence: Melt zone dispersivity and chromatography, J. Geophys. Res., this issue.

DePaolo, D. J., E. M. Stolper, and D. M. Thomas, Scientific opportunities from Deep Drilling in Hawaii, I, Physics and chemistry of plume-lithosphere interactions, Eos Trans. $A G U, 72,236-237,1991$.

Frey, F. A., W. S. Wise, M. O. Garcia, H. West, S.-T. Kwon, and A. Kennedy, Evolution of Mauna Kea volcano, Hawaii: Petrologic and geochemical constraints on postshield volcanism, $J$. Geophys. Res., 95, 1271-1300, 1990.

Hauri, E. H., J. A. Whitehead, and S. R. Hart, Fluid dynamic and geochemical aspects of entrainment in mantle plumes, $J$. Geophys. Res., 99, 24,275-24,300, 1994.

Hauri, E. H., J. C. Lassiter, and D. J. DePaolo, Osmium isotope systematics of drilled lavas from Mauna Loa, Hawaii, J. Geophys. Res., this issue.

Jackson, E. D., E. A. Silver, and G. B. Dalrymple, Hawaiian-Emperor chain and its relation to Cenozoic circumpacific tectonics, Geol. Soc. Am. Bull., 83, 601-618, 1972.

Kurz, M. D., T. C. Kenna, J. C. Lassiter, and D. J. DePaolo, Helium isotopic evolution of Mauna Kea volcano: First results from the 1-km drill core, J. Geophys. Res., this issue.

Lassiter, J. C., D. J. DePaolo and M. Tatsumoto, Isotopic evolution of Mauna Kea volcano: Results from the initial phase of the Hawaii Scientific Drilling Project, J. Geophys. Res., this issue.

Lipman, P. W., The southwest rift zone of Mauna Loa-Implications for structural evolution of Hawaiian volcanoes, $A m$. J. Sci., 280-A, 752-776, 1980.

Lipman, P. W., Declining growth of Mauna Loa during the last 100,000 years: Rates of lava accumulation vs. gravitational subsidence, in Mauna Loa Revealed: Structure, Composition, History, and Hazards, Geophys. Monogr. Ser., vol. 92, edited by J. M. Rhodes and J. P. Lockwood, pp. 45-80, AGU, Washington, D. C., 1995.

Lipman, P. W., and J. G. Moore, Mauna Loa lava accumulation rates at the Hilo drill site: Formation of lava delatas during a period of declining overall volcanic growth, J. Geophys. Res., this issue.

MacDougall, I., Potassium-argon ages from lavas of the Hawaiian Islands, Geol. Soc. Am. Bull., 75, 107-128, 1964.

Moore, J. G., Subsidence of the Hawaiian Ridge, U.S. Geol. Surv. Prof. Pap., 1350, 85-100, 1987.

Moore, J. G., and D. A. Clague, Volcano growth and evolution of the island of Hawaii, Geol. Soc. Am. Bull., 104, 1471-1484, 1992.
Moore, J. G., D. A. Clague, and W. R. Normark, Diverse basalt types from Loihi seamount, Hawaii, Geology, 10, 88-92, 1982.

Mark, R. K., and J. G. Moore, Slopes of the Hawaiian Ridge, U.S. Geol. Surv. Prof. Pap., 1350, 101-107, 1987.

Peterson, D. W., and R. B. Moore, Geologic history and evolution of geologic concepts, Island of Hawaii, U.S. Geol. Surv. Prof. Pap., $1350,149-189,1987$.

Rhodes, J. M., Geochemical stratigraphy of lavas flows sampled by the Hawaii Scientific Drilling Project, J. Geophys. Res., this issue.

Ribe, N. M., Dynamical geochemistry of the Hawaiian plume, Earth Planet. Sci. Lett., 88, 37-46, 1988.

Ribe, N., and U. Christensen, Three-dimensional modeling of plumelithosphere interaction, J. Geophys. Res., 99, 669-682, 1994.

Sharp, W. D., B. D. Turrin, P. R. Renne, and M. A. Lanphere, The ${ }^{40} \mathrm{Ar} /{ }^{39} \mathrm{Ar}$ and $\mathrm{K} / \mathrm{Ar}$ dating of lavas from the Hilo $1-\mathrm{km}$ core hole, Hawaii Scientific Drilling Project, J. Geophys. Res., this issue.

Sims, K. W. W., D. J. DePaolo, M. T. Murrell, W. S. Baldridge, S. J. Goldstein, and D. A. Clague, Mechanisms of magma generation beneath Hawaii and mid-ocean ridges: Uranium/thorium and samarium/neodymiun isotopic evidence, Science, 267, 508-512, 1995.

Stolper, E. M., D. J. DePaolo, and D. M. Thomas, Introduction to special section: Hawaii Scientific Drilling Project, J. Geophys. Res., this issue.

Turcotte, D. L., and G. Schubert, Geodynamics, 450 pp., John Wiley, New York, 1982.

Walcott, R., Flexure of the lithosphere at Hawaii, Tectonophysics, 9 , 435-446, 1970.

Walker, G. P. L., Geology and volcanology of the Hawaiian Islands, Pac. Sci., 44, 315-347, 1990.

Watson, S., and D. P. McKenzie, Melt generation by plumes: A study of Hawaiian volcanism, J. Petrol., 32, 501-537, 1991.

Watts, A. B., An analysis of isostasy in the world's oceans, 1, The Hawaiian-Emperor seamount chain, J. Geophys. Res., 83, 59896004, 1978.

Yang, H.-J., F. A. Frey, M. O. Garcia, and D. A. Clague, Submarine lavas from Mauna Kea volcano, Hawaii: Implications for Hawaiian shield-stage processes, J. Geophys. Res., 99, 15,577-15,594, 1994.

Yang, H.-J., F. A. Frey, J. M. Rhodes, and M. O. Garcia, Evolution of Mauna Kea volcano: Inferences from lava compositions recovered in the Hawaii Scientific Drilling Project, J. Geophys. Res., this issue.

D. J. DePaolo, Department of Geology and Geophysics, University of California, Berkeley, CA 94720-4767. (e-mail: depaolo@garnet. berkeley.edu)

E. M. Stolper, Division of Geological and Planetary Sciences, MS170-25, California Institute of Technology, Pasadena, CA 91125. (e-mail: ems@expet.gps.caltech.edu)

(Received July 19, 1995; revised December 19, 1995; accepted January 4, 1996.) 